\title{
Phase I/II Clinical Trials Using Gene-Modified Adult Hematopoietic Stem Cells for HIV: Lessons Learnt
}

\author{
Ronald T. Mitsuyasu, ${ }^{1}$ Jerome A. Zack, ${ }^{2}$ Janet L. Macpherson, ${ }^{3}$ and Geoff P. Symonds ${ }^{4}$ \\ ${ }^{1}$ Center for Clinical AIDS Research and Education (CARE Center), University of California-Los Angeles, Los Angeles, CA 90035, \\ USA \\ ${ }^{2}$ Departments of Medicine and of Microbiology, Immunology and Molecular Genetics, University of California-Los Angeles, Los Angeles, \\ CA 90095, USA \\ ${ }^{3}$ SpanCyte Pty Ltd., B.O. Box 960, Sydney, Leichhardt, NSW 2040, Australia \\ ${ }^{4}$ Faculty of Medicine and Centre for Applied Medical Research, St. Vincent's Hospital, The University of New South Wales, Kensington, \\ Sydney, NSW 2052, Australia \\ Correspondence should be addressed to Geoff P. Symonds, geoff@sympracs.com
}

Received 10 January 2011; Accepted 15 March 2011

Academic Editor: Dominique Bonnet

Copyright ( $) 2011$ Ronald T. Mitsuyasu et al. This is an open access article distributed under the Creative Commons Attribution License, which permits unrestricted use, distribution, and reproduction in any medium, provided the original work is properly cited.

Gene therapy for individuals infected with HIV has the potential to provide a once-only treatment that will act to reduce viral load, preserve the immune system, and mitigate cumulative toxicities associated with highly active antiretroviral therapy (HAART). The authors have been involved in two clinical trials (phase I and phase II) using gene-modified adult hematopoietic stem cells (HSCs), and these are discussed as prototypic trials within the general field of HSC gene therapy trials for HIV. Taken as a group these trials have shown (i) the safety of both the procedure and the anti-HIV agents themselves and (ii) the feasibility of the approach. They point to the requirement for (i) the ability to transduce and infuse as many as possible gene-containing HSC and/or (ii) high engraftment and in vivo expansion of these cells, (iii) potentially increased efficacy of the anti-HIV agent(s) and (iv) automation of the cell processing procedure.

\section{Introduction}

Highly active antiretroviral therapy (HAART) has greatly improved disease management for individuals infected with HIV-1. However, it is often associated with toxicities, adverse interactions with other drugs, and the emergence of viral resistance [1]. The search for an HIV-1 vaccine has been disappointing [2]. Gene-based therapies aim to inhibit HIV replication by the use of an anti-HIV gene expressed intracellularly; such genes include ribozyme, antisense, aptamer, RNAi, zinc finger nuclease, dominant negative protein, fusion inhibitor, intracellular antibody, and viral decoy approaches [3-35]. Some of these genes have been shown to be safe in phase I clinical trials $[4,10,12,17,20,28-$ 35]. Ribozymes are small catalytic RNA molecules that can be engineered to target specific RNA sequences $[4,10,19,20$, $24,26,27,31,32,35-40]$.
The gene therapy vector OZ1 (also termed RRz2 in publications) comprises a Moloney murine leukemia virusbased, replication-incompetent gamma retroviral vector (LNL6) containing a gene that encodes a ribozyme targeting the overlapping vpr and tat reading frames of HIV-1 [4, $32,36-39]$. OZ1 has been shown to inhibit the replication of laboratory and clinical isolates of HIV-1 in vitro [3639]. Resistance mutations in the region of HIV-1 targeted by $\mathrm{OZ} 1$ were not observed in long-term cell culture [10, $27,37,39]$. The concept tested in the two clinical trials conducted by the present investigators and colleagues (phase I and phase II) was that, OZ1-transduced CD34+ HSC would engraft, divide, and differentiate in vivo to produce a pool of mature myeloid and lymphoid cells protected from productive HIV-1 replication and, in the case of the phase II trial, that this protection could be measured by differences in plasma HIV-1 RNA levels in the absence of 
antiretroviral therapy [32]. This concept is shown pictorially in Figure 1. In both these prototypic trials, autologous CD34+ HSC were transduced and administered without the subject undergoing myeloablation or any form of bone marrow conditioning.

\section{Prototypic Phase I Trial Design}

The prototypic phase I clinical trial [4] was conducted using CD34+ HSC to assess the safety and feasibility of ex vivo transduction and reinfusion of autologous OZ1transduced cells. The protocol involved injection of the subjects with G-CSF to mobilize HSC into the peripheral blood, collection of the mononuclear cell fraction by apheresis, selection of the CD34+ population, culture of these cells in vitro with cytokines, their transduction with control (LNL6) or therapeutic (OZ1) vectors, and finally cell harvest and infusion (see Figure 2). This trial demonstrated that the approach was safe and technically feasible and that concurrent administration of antiretroviral therapy did not inhibit stem cell mobilization or the ability to transduce HSC in vitro. There were no serious adverse events related to the gene transfer process or the gene transfer product during the study period or the subsequent long-term safety followup. Detection of the gene in peripheral blood cells and bone marrow cells was found in some patients to be present out to 3 years after a single infusion of these cells [4].

\section{Prototypic Phase II Trial Design}

In this randomized trial [32], subjects (1:1 randomization) were infused with either gene or sham medium only transduced autologous CD34+ HSC. The protocol of cell selection, culture, and transduction was based on the phase I trial, with some modifications. In addition (unlike the phase I trial), the protocol included two antiretroviral treatment interruptions (ATIs) to provide positive selective pressure for OZ1-protected cells, and as a read-out for the effectiveness of these protected cells in preventing further HIV replication in vivo (see Figures 3(a) and 3(b)). The impact of OZ1 on plasma HIV-1 viral load was assessed at the end of the second eight-week ATI (the primary endpoint). Secondary endpoints of quantitative marking (presence of gene) and expression (active RNA form) of OZ1, timeweighted area under the curve for viral load (TWAUC), $\mathrm{CD} 4+\mathrm{T}$ lymphocyte count in absolute and percentage of $\mathrm{T}$ lymphocytes (CD4\%), presence of HIV-1 proviral DNA, and thymic function ( $\mathrm{T}$ cell receptor excision circles, TREC) were assessed at the primary endpoint (weeks 47/48) and to week 100. The OZ1 treatment group participants are now enrolled in a long-term safety followup protocol.

\section{Regulatory Process}

For the prototypic trials, approval was obtained from the relevant Institutional Review Boards/Human Research Ethics Committee as well as the Recombinant DNA Advisory Committee (RAC), the Center for Biologics Evaluation and
Research (CBER), the United States Food and Drug Administration (FDA), and the Australian Therapeutic Goods Administration (TGA). Safety parameters were assessed in accordance with RAC, CBER, FDA, and TGA recommendations [41]. The majority of the other trials followed similar routes of approval, predominantly in the USA (see Table 1).

\section{Cell Processing}

In both the prototypic phase I and phase II clinical trials the cell processing involved the elements as depicted in Figures 2 and 3(a). Apheresis was performed using the COBE Spectra Apheresis System (Gambro) and the mononuclear cell fraction subjected to CD34+ cell selection using the CEPRATE SC Stem Cell Concentration System (CellPro Inc) (initial subjects in phase I trial) [4] or the Isolex 300i Cell Selection System (Nexell Therapeutics) (all other subjects phase I and II trials) [4, 32].

5.1. Phase I Trial [4]. The CD34+ selected cell population was placed into tissue culture with Iscove's Modified Dulbecco's Medium (IMDM) containing the cytokines stem cell factor (SCF) and megakaryocyte growth and development factor (MGDF) at a concentration of $50 \mathrm{ng} / \mathrm{mL}$ and $100 \mathrm{ng} / \mathrm{mL}$, respectively (Amgen Inc). Cells were split into two equal aliquots and transduced on day 2 with either an LNL6 control or the OZ1 retroviral vectors (Figure 2). In the 7 latter subjects, transduction was improved by the use of RetroNectin resulting in a range of transduction from 7 to $57 \%$. Cells were collected on day 3 , and after release testing, the two separately transduced HSC aliquots were combined and infused into the subject from whom they were obtained. The number of CD34+ HSC infused was in the range of $1-10 \times 10^{6} / \mathrm{kg}$.

5.2. Phase II Trial [32]. Similar to the phase I trial, the CD34+ selected cell population was placed into tissue culture with Iscove's Modified Dulbecco's Medium (IMDM) containing the cytokines stem cell factor (SCF) (Amgen) and megakaryocyte growth and development factor (MGDF) (Takara) at a concentration of $50 \mathrm{ng} / \mathrm{mL}$ and $100 \mathrm{ng} / \mathrm{mL}$, respectively. However in this case, subjects were randomized to receive either sham (medium alone) or OZ1-transduced CD34+ HSC (Figure 3(a)). Both treatment groups received an equivalent dose of viable CD34+ cells $/ \mathrm{kg}\left(9 \times 10^{6} / \mathrm{kg}\right)$ and the infused cell product in the OZ1 treatment group contained a mean of $54.0 \%$ OZ1-containing cells. Participants in the OZ1 group are now enrolled in a separate longterm follow-up protocol which will continue for at least 15 years. To date, the longest follow-up period from the time of infusion of the first participant is 6.5 years [32].

\section{OZ1 Gene Marking (DNA) and OZ1 Expression (RNA)}

In the prototypic phase I trial [4], hematopoietic progeny cells containing either the LNL6 vector or OZ1 (derived from the gene-modified CD34+ HSC) could be separately 


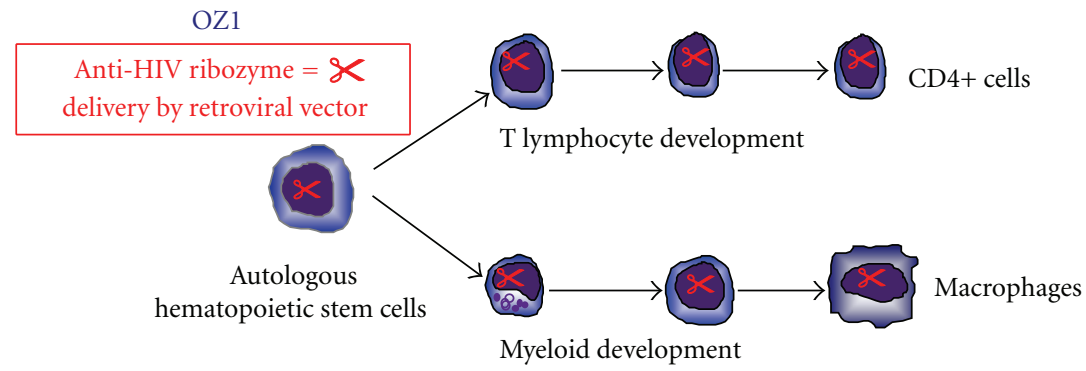

Figure 1: The figure shows the concept of introducing an anti-HIV gene (in this case a ribozyme) into hematopoietic stem cells. As these cells mature and differentiate into T lymphocytes and myeloid cells, the anti-HIV gene is expressed in these cells potentially providing an anti-HIV effect in cells susceptible to HIV.

TABLE 1

\begin{tabular}{|c|c|c|}
\hline $\begin{array}{l}\text { Target/mechanism of } \\
\text { action }\end{array}$ & Construct & Results \\
\hline $\operatorname{Rev}[30]$ & $\begin{array}{l}\text { "Humanized" dominant-negative REV protein } \\
\text { (huM10) and nontranslated marker gene (FX) as an } \\
\text { internal control in retroviral vector }\end{array}$ & $\begin{array}{l}\text { Gene marking in first months, then low or } \\
\text { undetectable except in one patient when viral load } \\
\text { increased. No serious adverse events. }\end{array}$ \\
\hline RRE decoy $[12,33]$ & $\begin{array}{l}\text { Retroviral-mediated transfer of an RRE decoy gene } \\
\text { into bone marrow CD } 34+\text { cells }\end{array}$ & $\begin{array}{l}\text { No adverse effects. } 2 \text { subjects' cells detected } \\
\text { containing both the RRE and LN vectors on the day } \\
\text { after cell infusion. All subsequent samples negative for } \\
\text { the L-RRE-neo vector. Cells containing the control LN } \\
\text { vector detected up to } 330 \text { days. }\end{array}$ \\
\hline Rev/tat ribozyme [34] & $\begin{array}{l}\text { Tat and tat/rev ribozyme in autologous CD } 34+\text { cells } \\
\text { and empty vector backbone in two patient groups } \\
\text { with and without ablation }\end{array}$ & $\begin{array}{l}\text { Trial } 1: 3 / 5 \text { patients showed low-frequency marking of } \\
\text { PBMC with ribozyme and vector backbone. Trial } 2 \text { : } \\
\text { gene marked cells detected after infusion and to } 1 \text { year } \\
\text { and RNA expression detected. }\end{array}$ \\
\hline Tat/vpr ribozyme [4] & $\begin{array}{l}\text { Phase I study: Moloney murine leukemia retroviral } \\
\text { vector encoding a ribozyme versus control LNL6 } \\
\text { vector in CD34+ HPSC }\end{array}$ & $\begin{array}{l}\text { De novo production of myeloid and lymphoid cells. } \\
\text { Degree of persistence of gene-containing cells } \\
\text { dependent on transduced cell dose. }\end{array}$ \\
\hline Tat/vpr ribozyme [32] & $\begin{array}{l}\text { Phase II study: Moloney murine leukemia } \\
\text { virus-based, replication-incompetent gamma } \\
\text { retroviral vector with gene encoding a ribozyme vs } \\
\text { placebo in CD34+ cells }\end{array}$ & $\begin{array}{l}\text { No significant difference mean plasma viral load at } \\
\text { primary endpoint but lower TWAUC and other } \\
\text { indicators of biologic effect. No safety concerns. }\end{array}$ \\
\hline $\begin{array}{l}\text { Tat/rev, CCR5, TAR } \\
\text { decoy [35] }\end{array}$ & $\begin{array}{l}\text { Tat/rev short hairpin RNA, TAR decoy, and CCR } 5 \\
\text { ribozyme expressed from a self-inactivating lentiviral } \\
\text { vector transduced in CD } 34+\text { cells, along with standard } \\
\text { unmanipulated HPCs in } 4 \text { patients with HIV and } \\
\text { non-Hodgkin's lymphoma }\end{array}$ & $\begin{array}{l}\text { Engraftment by } 11 \text { days. Low levels of gene marking } \\
\text { observed up to } 24 \text { months. }\end{array}$ \\
\hline
\end{tabular}

monitored in the subjects, and it was estimated that $0.001-$ $0.01 \%$ gene-containing progeny cells were present in the subjects' peripheral blood. Transgene expression was shown in peripheral blood mononuclear cells and T-cell subsets including naive (CD45RA+CD62L+) T lymphocytes. In the phase II trial [32], OZ1 gene marking (DNA) and expression (RNA) were also assessed, with the degree of gene marking in peripheral blood mononuclear cells higher than in the phase I trial at $0.01-0.38 \%$.

\section{Efficacy in Phase II Trial [32]}

Statistical evidence of antiretroviral efficacy found in the phase II trial was as follows (OZ1 versus control):

(1) Plasma viral load; (a) greater number of subjects with a plasma viral load of less than $4 \log _{10}$ copies/mL at weeks 47/48 (15/32 versus 5/33) $(P=.009)$;

(b) longer median time (36 versus 24 days) to reach $4 \log _{10}$ copies/mL viral load during the analytic treatment interruption.

(2) The time-weighted area under the log viral load curve (TWAUC) was statistically lower in the OZ1 group (weeks 40-48; median difference $-0.34 \log _{10}$ copies/ml/day, $P=.024$ and weeks 40-100; median difference $-0.37 \log _{10}$ copies $/ \mathrm{ml} /$ day, $P=.034$ ).

(3) The number of participants with a TWAUC in the lowest quartile during weeks $40-100$ was statistically 


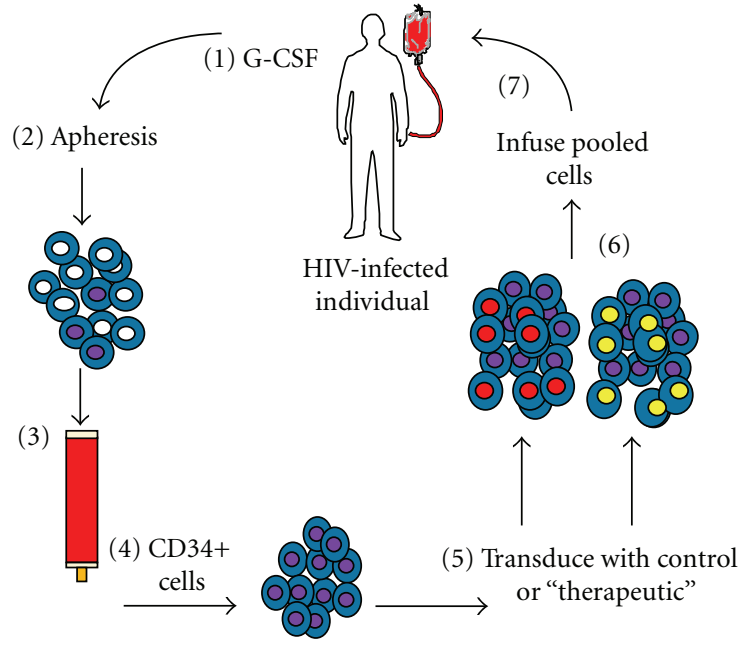

() Peripheral blood mononuclear cells

() $\mathrm{CD} 34+$ hematopoietic stem cells

() "Therapeutic" transduced CD34+ hematopoietic stem cells

() Control vector transduced CD34+ hematopoietic stem cells

Figure 2: The figure shows the prototypic phase I trial design in which CD34+ HSC were obtained from post G-CSF apheresis product that is $\mathrm{CD} 34+$ selected. The $\mathrm{CD} 34+$ cells were then transduced with either control or OZ1-containing vector and both transduced populations (control and OZ1) mixed and infused into the individual. (1) Subjects are injected with a course of G-CSF to mobilize CD34+ HSC from the bone marrow to the peripheral blood. (2) Apheresis product is obtained. (3) The mononuclear cell fraction is applied to a CD34+ isolation system. (4) CD34+ cells are obtained. (5) These are transduced with either control or OZ1containing vector (50\% of each) to obtain (6) A mixed population of control and OZ1 transduced cells. (7) This mixed population is infused back into the individual.

greater in the OZ1 group (OZ1 $n=12 ; 37.5 \%$, Control $n=5 ; 15.2 \%, P=.04)$.

(4) Median plasma viral load in the OZ1 participants who continued to display OZ1 expression in PBMC at any time point beyond week 48 (3.81 $\log _{10} 95 \%$ CI; median 3.18-4.23; $n=15$ ) was significantly lower than that in the control participants $(4.58$ $\log _{10} 95 \% \mathrm{CI}$; median 4.31-4.83; $\left.n=33\right)(P=$ $.003)$. The median TWAUC from weeks $40-48$ in these $\mathrm{OZ1}$ participants $\left(3.44 \log _{10}\right.$ copies $/ \mathrm{ml} /$ day, $n=$ 15) was significantly lower than that in the control participants (3.93 $\log _{10}$ copies/ml/day, $\left.n=33\right)(P=$ $.03)$ as was the median TWAUC from weeks 40-100 (3.97 $\log _{10}$ copies/ml/day, $n=15$ ) in comparison to the control group (4.53 $\log _{10}$ copies/ml/day, $n=33$ ) $(P=.005)$.

Other trends were as follows.

(1) Mean plasma viral load was lower in the OZ1 group at $47 / 48$ week (primary endpoint).
(2) During the analytic treatment interruption, 17 (45\%) participants in the OZ1 group reinitiated HAART compared to $22(61 \%)$ control participants.

(3) Median time to reinitiate antiretroviral therapy during analytic treatment interruption was 29.4 weeks in the control group $(n=22,61 \%)$ and for the OZ1 group was greater than 60 weeks.

(4) CD4+ T lymphocyte numbers and \% CD4 were higher, and CD8+ T lymphocyte numbers lower, in the $\mathrm{OZ1}$ group.

\section{Safety Evaluations in Prototypic Trials in addition to SAEs}

In both prototypic phase I and II clinical trials no replicationcompetent retrovirus was detected at any time point. In both trials no clonal expansion of hematopoietic cells or other event suggestive of insertional mutagenesis was observed; predominant integration site analysis was only required in the phase II trial. The OZ1 target sequence in the HIV1 plasma RNA was assessed over time, and there was no modification at the ribozyme recognition site to prevent cleavage, or to drive the evolution of resistant virus.

\section{Summary of Other Stem Cell Trials for HIV/AIDS}

Other trials that have been conducted in stem cells for the indication of HIV/AIDS are summarized in Table 1.

\section{Discussion}

Gene therapy for HIV-positive individuals has the potential to provide a once-only treatment that reduces viral load, preserves the immune system, and avoids cumulative toxicities associated with HAART. The two prototypic clinical trials (phase I and phase II) described used tat/vpr-specific anti-HIV ribozyme (OZ1) gene-modified autologous HSC. In these two trials, 10 subjects [4] and 74 subjects [32] were treated, respectively.

These and trials from other investigators have shown the safety of the procedure and the anti-HIV agents themselves as well as the feasibility of the approach in which autologous CD34+ HSC are taken from the subject, genetically manipulated and given back to the subject. In addition, the phase II trial demonstrated a significant biologic effect.

The rationale for the prototypic trials was to demonstrate a "HAART-sparing" function of the therapy, that is, the ability to decrease, partially or totally, the need for HAART. While an antiretroviral effect was seen in the phase II study, it was relatively modest.

Taken together with the other stem cell trials summarised, areas for focus appear to be (i) maximizing the number of gene-containing HSC transduced and infused and/or (ii) maximizing the engraftment, proliferation, and differentiation of these gene-modified cells, possibly by 


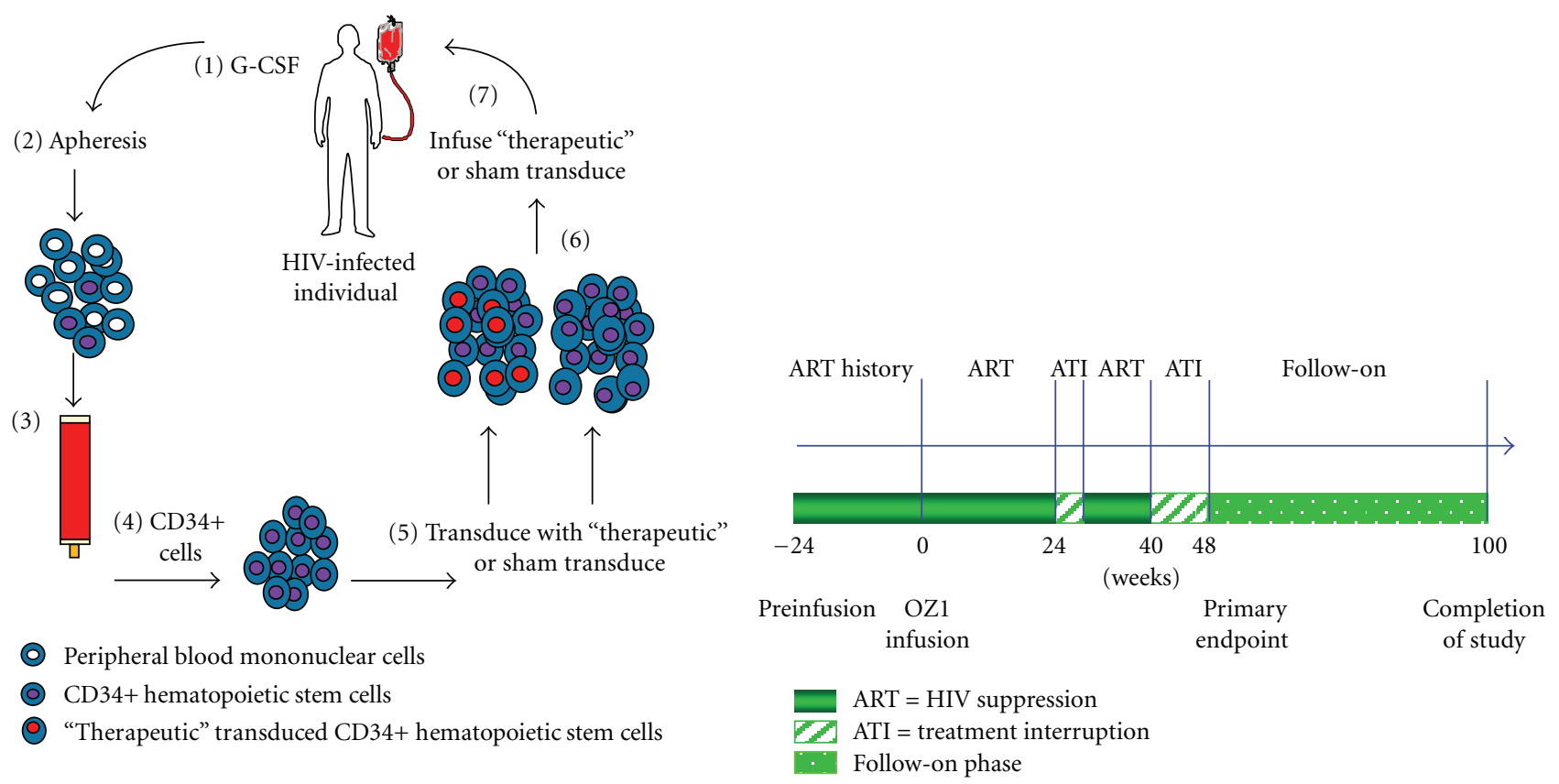

(a) Prototypic phase II trial

(b) Design prototypic phase II trial

FIgURE 3: (a) The figure shows the prototypic phase II trial design in which CD34+ HSC are obtained from apheresis product that is $\mathrm{CD} 34+$ selected. The cells were then transduced with either sham (medium only) or OZ1-containing vector and that population (control or OZ1) infused into the individual. (1) Subjects are injected with a course of G-CSF to mobilize CD34+ HSC from the bone marrow to the peripheral blood. (2) Apheresis product is obtained. (3) The mononuclear cell fraction is applied to a CD34+ isolation system. (4) CD34+ cells are obtained. (5) These are sham transduced (medium alone) or transduced with OZ1 to obtain (6) a control population or OZ1 tranduced cells. (7) This population is infused back into the individual. (b) The figure shows the schedule for the phase II clinical trial. ART, antiretroviral therapy; ATI: analytic treatment interruption. The primary endpoint was viral load at weeks 47/48. Other end-points were area under the viral load curve weeks $40-48$ and $40-100$.

incorporating partial myeloablation; (iii) potentially increasing the effectiveness of the anti-HIV gene(s) used and (iv) automation of the cell processing procedure. Each of these points are discussed here.

10.1. Number of Gene-Containing HSC and Subsequent Engraftment. In both prototypic clinical trials, a dose of 10 $\times 10^{6} \mathrm{CD} 34+\mathrm{HSC} / \mathrm{kg}$ could be achieved. Improvements in mobilisation, CD34+ cell collection, and transduction compared to the phase I study [4] resulted in a mean transduced CD34+ cell dose of $5 \times 10^{6}$ cells $/ \mathrm{kg}$ and an increase (approximate $2 \log _{10}$ ) in the frequency of OZ1containing cells in the peripheral blood. In both trials (reflected in results from other investigator trials), the frequency of gene-containing cells in the peripheral blood decreased over time indicating a need to potentially take care of one or several of the following in relation to the HSC: (i) maximizing the number of gene-modified cells, (ii) maximizing the degree of engraftment, (iii) increasing the degree of proliferation and differentiation, (iv) infusing on more than one occasion.

It is relevant that, in each trial, transduced HSC infusion resulted in gene marking in peripheral blood of only a maximum of $0.01 \%$ (phase I trial) [4] and $0.38 \%$ (phase II trial) [32]. It is significant that mathematical modeling undertaken prior to the phase II trial [42] predicted that, during the analytic treatment interruption, OZ1 recipients would experience an initial increase in HIV-1 viral load followed by the establishment of a lower set point. This is indeed the result that was seen in the phase II trial itself [32]. The model predicted that the establishment of OZ1 CD $34+$ cells in the bone marrow at approximately $5-10 \%$ of total CD34+ cell population could reduce viral load by $0.5 \log _{10}$ in one year. In this phase II study, bone marrow aspiration was not performed, and hence the percentage engraftment is not known. Based on the frequency of cells containing OZ1 in the Phase II trial $(0.01 \%$ to $0.38 \%)$ in the peripheral blood, it can be inferred that engraftment was substantially lower than $5-10 \%$. Previous studies have also shown that, in the absence of strong selective pressure, peripheral blood reconstitution with gene-containing cells is limited [43-46]. Given the engraftment and gene expression results in the phase II study [32], the antiretroviral effect of OZ1 was greater than predicted by the modelling. Candidate mechanisms for this additional effect include an impact of OZ1 on cell-to-cell transmission in the lymphatic system, compartmentalisation such that the number of OZ1containing cells in the peripheral blood is not representative of the survival of OZ1-containing cells in sequestered foci (e.g., the bone marrow and various lymphatic tissues, such as the GI lymphoid pool), and perhaps protection of particular cell subpopulations such as antigen-presenting 
cells (including dendritic cells and macrophages) or HIVspecific CD4+ T lymphocytes. A recent report [47] suggests that early hematopoietic progenitor cells in the bone marrow might be infected with HIV. It is possible that OZ1 in our phase II study targeted this reservoir, and this could allow for a larger biologic effect than that predicted by the mathematical model.

It is also of high interest to explore ways to expand and ensure efficient engraftment in vivo by use of factors such as SDF-1 and growth factors/cytokines/differentiation factors. Therefore, by increasing the transduction efficiency, facilitating engraftment of these reinfused cells, and potentially using multiple infusions of transduced cells over time, it may be possible to increase the number of these gene-protected cells to see an even greater antiretroviral effect in the future.

10.2. Increased Efficacy of the Anti-HIV Agent and Potential Use in Different Patient Populations. In both clinical trials, the gene transfer agent was a retroviral vector delivering a tat/vpr-specific anti-HIV ribozyme. While effective at inhibiting HIV in tissue culture systems, it may be that this agent will need to be used in combination with other antiHIV genes or other agents to produce a greater therapeutic effect and to overcome potential resistance. The use of multiple agents targeting several sites in the viral replication cycle is now a well-established concept in anti-HIV therapy.

In the phase I and phase II trials described here, individuals were recruited who were on a relatively (phase I) or fully (phase II) effective HAART regimen. Future evaluation may include individuals prior to HAART initiation in whom viral load (and hence selective pressure for gene-containing cells) will be higher without the need for treatment interruptions. Other potential patient groups consist of individuals who are multidrug resistant or have AIDS and have no other options for therapy. It should be possible to trial this therapy on these varying patient populations and eventually there may be an indication that includes all HIV positive individuals.

10.3. Automation of Cell Processing. The cell processing procedures used in the phase I and II trials were multistep, requiring skilled operators and a variety of equipment/devices. Automation of this process, using a completely closed system, would be highly desirable to (i) reduce operator time and effort and the potential for errors, (ii) potentially increase reproducibility and reliability of the approach, and (iii) avoid the risk of contamination. Such an automated and closed system would be highly desirable for high patient access and reduced cost of cell processing.

\subsection{Areas for Maximizing Effect. These can be summarized} as

(i) number of gene-containing cells in the peripheral blood and lymphatic tissue;

(ii) apparent efficacy of anti-HIV agent;

(iii) improve relatively laborious cell processing.
10.5. Positive Outcomes. Notwithstanding the areas for maximizing effect, the prototypic studies indicate that OZ1 celldelivered gene therapy is safe and has antiretroviral activity, albeit modest. Our phase II trial also showed that a large number of subjects (74) can be treated similarly at several (3) distinct clinical sites, indicating that this type of approach can be scaledup to treat substantial numbers of patients, if personnel at the clinical site are properly trained in cell processing and delivery. These trials show the potential of the gene therapy approach for the treatment of HIV-1 and represent a major advance in the field.

\section{Acknowledgments}

The authors acknowledge that the prototypic trials commented upon here in the context of the wider field of gene therapy for HIV were supported by Gene Shears Pty Limited and Johnson \& Johnson. The results of these trials (termed prototypic in the text) have been published and discussed previously. The views expressed in this paper are by way of commentary subsequent to prototypic trials and other publications and are strictly the authors own.

\section{References}

[1] B. S. Taylor, M. E. Sobieszczyk, F. E. McCutchan, and S. M. Hammer, "The challenge of HIV-1 subtype diversity," The New England Journal of Medicine, vol. 358, no. 15, pp. 1590-1602, 2008.

[2] D. I. Watkins, D. R. Burton, E. G. Kallas, J. P. Moore, and W. C. Koff, "Nonhuman primate models and the failure of the Merck HIV-1 vaccine in humans," Nature Medicine, vol. 14, no. 6, pp. 617-621, 2008.

[3] D. Baltimore, "Intracellular immunization," Nature, vol. 335, no. 6189, pp. 395-396, 1988.

[4] R. G. Amado, R. T. Mitsuyasu, J. D. Rosenblatt et al., "Antihuman immunodeficiency virus hematopoietic progenitor cell-delivered ribozyme in a phase I study: myeloid and lymphoid reconstitution in human immunodeficiency virus type-1-infected patients," Human Gene Therapy, vol. 15, no. 3, pp. 251-262, 2004.

[5] S. A. Dong, R. E. Donahue, M. Kamata et al., "Stable reduction of CCR5 by RNAi through hematopoietic stem cell transplant in non-human primates," Proceedings of the National Academy of Sciences of the United States of America, vol. 104, no. 32, pp. 13110-13115, 2007.

[6] J. Anderson, M. J. Li, B. Palmer et al., "Safety and efficacy of a lentiviral vector containing cthree anti-HIV genesCCR5 ribozyme, tat-rev siRNA, and TAR decoy-in SCID-hu mouse-derived t cells," Molecular Therapy, vol. 15, no. 6, pp. 1182-1188, 2007.

[7] I. Bahner, C. Zhou, X. J. Yu, Q. L. Hao, J. C. Guatelli, and D. B. Kohn, "Comparison of trans-dominant inhibitory mutant human immunodeficiency virus type 1 genes expressed by retroviral vectors in human T lymphocytes," Journal of Virology, vol. 67, no. 6, pp. 3199-3207, 1993.

[8] L. Cagnon and J. Rossi, "Retroviral delivery and anti-HIV testing of hammerhead ribozymes," Methods in Molecular Biology, vol. 74, pp. 451-457, 1997. 
[9] B. Dropulic, D. A. Elkins, J. J. Rossi, and N. Sarver, "Ribozymes: use as Anti-HIV therapeutic molecules," Antisense Research and Development, vol. 3, no. 1, pp. 87-94, 1993.

[10] G. Fanning, R. Amado, and G. Gymonds, "Gene therapy for HIV/AIDS: the potential for a new therapeutic regimen," Journal of Gene Medicine, vol. 5, no. 8, pp. 645-653, 2003.

[11] D. B. Kohn, "Gene therapy using hematopoietic stem cells," Current Opinion in Molecular Therapeutics, vol. 1, no. 4, pp. 437-442, 1999.

[12] D. B. Kohn, G. Bauer, C. R. Rice et al., "A clinical trial of retroviral-mediated transfer of a rev-responsive element decoy gene into CD34 cells from the bone marrow of human immunodeficiency virus-1-infected children,” Blood, vol. 94, no. 1, pp. 368-371, 1999.

[13] M. Li, H. Li, and J. J. Rossi, "RNAi in combination with a ribozyme and TAR decoy for treatment of HIV infection in hematopoietic cell gene therapy," Annals of the New York Academy of Sciences, vol. 1082, pp. 172-179, 2006.

[14] A. S. Lo, Q. Zhu, and W. A. Marasco, "Intracellular antibodies (intrabodies) and their therapeutic potential," Handbook of experimental pharmacology, no. 181, pp. 343-373, 2008.

[15] W. A. Marasco, J. Lavecchio, and A. Winkler, "Human antiHIV-1 tat sFv intrabodies for gene therapy of advanced HIV1 - infection and AIDS," Journal of Immunological Methods, vol. 231, no. 1-2, pp. 223-238, 1999.

[16] M. R. Mautino and R. A. Morgan, "Potent inhibition of human immunodeficiency virus type 1 replication by conditionally replicating human immunodeficiency virusbased lentiviral vectors expressing envelope antisense mRNA," Human Gene Therapy, vol. 11, no. 14, pp. 2025-2037, 2000.

[17] R. A. Morgan, R. Walker, C. S. Carter et al., "Preferential survival of CD4+ $\mathrm{T}$ lymphocytes engineered with antihuman immunodeficiency virus (HIV) genes in HIV-infected individuals," Human Gene Therapy, vol. 16, no. 9, pp. 10651074, 2005.

[18] K. V. Morris and J. J. Rossi, "Lentivirus-mediated RNA interference therapy for human immunodeficiency virus type 1 infection," Human Gene Therapy, vol. 17, no. 5, pp. 479-486, 2006.

[19] J. J. Rossi, "The application of ribozymes to HIV infection," Current Opinion in Molecular Therapeutics, vol. 1, no. 3, pp. 316-322, 1999.

[20] D. S. Strayer, R. Akkina, B. A. Bunnell et al., "Current status of gene therapy strategies to treat HIV/AIDS," Molecular Therapy, vol. 11, no. 6, pp. 823-842, 2005.

[21] J. A. Taylor, L. Vojtech, I. Bahner et al., "Foamy virus vectors expressing anti-HIV transgenes efficiently block HIV-1 replication," Molecular Therapy, vol. 16, no. 1, pp. 46-51, 2008.

[22] D. von Laer, S. Hasselmann, and K. Hasselmann, "Gene therapy for HIV infection: what does it need to make it work?" Journal of Gene Medicine, vol. 8, no. 6, pp. 658-667, 2006.

[23] R. C. Zahn, F. G. Hermann, E. Y. Kim et al., "Efficient entry inhibition of human and nonhuman primate immunodeficiency virus by cell surface-expressed gp41-derived peptides," Gene Therapy, vol. 15, no. 17, pp. 1210-1222, 2008.

[24] N. Sarver, E. M. Cantin, P. S. Chang et al., "Ribozymes as potential anti-HIV-1 therapeutic agents," Science, vol. 247, no. 4947, pp. 1222-1225, 1990.

[25] A. Schambach, B. Schiedlmeier, K. Kühlcke et al., "Towards hematopoietic stem cell-mediated protection against infection with human immunodeficiency virus," Gene Therapy, vol. 13, no. 13, pp. 1037-1047, 2006.
[26] J. J. Rossi, C. H. June, and D. B. Kohn, "Genetic therapies against HIV," Nature Biotechnology, vol. 25, no. 12, pp. 14441454, 2007.

[27] J. L. Macpherson, J. A. Ely, L. Q. Sun, and G. P. Symonds, "Ribozymes in gene therapy of HIV-1," Frontiers in Biosciencey, vol. 4, pp. D497-D505, 1999.

[28] B. L. Levine, L. M. Humeau, J. Boyer et al., "Gene transfer in humans using a conditionally replicating lentiviral vector," Proceedings of the National Academy of Sciences of the United States of America, vol. 103, no. 46, pp. 17372-17377, 2006.

[29] J. L. Macpherson, M. P. Boyd, A. J. Arndt et al., "Longterm survival and concomitant gene expression of ribozymetransduced CD4+ T-lymphocytes in HIV-infected patients," Journal of Gene Medicine, vol. 7, no. 5, pp. 552-564, 2005.

[30] G. M. Podsakoff, B. C. Engel, D. A. Carbonaro et al., "Selective survival of peripheral blood lymphocytes in children with HIV-1 following delivery of an anti-HIV gene to bone marrow CD34+ cells," Molecular Therapy, vol. 12, no. 1, pp. 77-86, 2005.

[31] G. P. Symonds, H. A. Johnstone, M. L. Millington, M. P. Boyd, B. P. Burke, and L. R. Breton, "The use of cell-delivered gene therapy for the treatment of HIV/AIDS," Immunologic Research, vol. 48, no. 1-3, pp. 84-98, 2010.

[32] R. T. Mitsuyasu, T. C. Merigan, A. Carr et al., "Phase 2 gene therapy trial of an anti-HIV ribozyme in autologous CD34 ${ }^{+}$ cells," Nature Medicine, vol. 15, no. 3, pp. 285-292, 2009.

[33] G. Bauer, D. Selander, B. Engel et al., "Gene therapy for pediatric AIDS," Annals of the New York Academy of Sciences, vol. 918, pp. 318-329, 2000.

[34] A. Michienzi, D. Castanotto, N. Lee, S. Li, J. A. Zaia, and J. J. Rossi, "RNA-mediated inhibition of HIV in a gene therapy setting," Annals of the New York Academy of Sciences, vol. 1002, pp. 63-71, 2003.

[35] D. L. DiGiusto, A. Krishnan, L. Li et al., "RNA-based gene therapy for HIV with lentiviral vector-modified CD34+ cells in patients undergoing transplantation for AIDS-related lymphoma," Science Translational Medicine, vol. 2, no. 36, p. 43, 2010.

[36] L. Q. Sun, J. A. Ely, W. Gerlach, and G. Symonds, "Anti-HIV Ribozymes," Molecular Biotechnology, vol. 7, no. 3, pp. 241251, 1997.

[37] L. Q. Sun, L. Wang, W. L. Gerlach, and G. Symonds, "Target sequence-specific inhibition of HIV-1 replication by ribozymes directed to tat RNA," Nucleic Acids Research, vol. 23, no. 15, pp. 2909-2913, 1995.

[38] L. Q. Sun, J. Pyati, J. Smythe et al., "Resistance to human immunodeficiency virus type 1 infection conferred by transduction of human peripheral blood lymphocytes with ribozyme, antisense, or polymeric trans-activation response element constructs," Proceedings of the National Academy of Sciences of the United States of America, vol. 92, no. 16, pp. 7272-7276, 1995.

[39] L. I. Wang, C. Witherington, A. King et al., "Preclinical characterization of an anti-tat ribozyme for therapeutic application," Human Gene Therapy, vol. 9, no. 9, pp. 1283-1291, 1998.

[40] J. J. Rossi, "Ribozyme therapy for HIV infection," Advanced Drug Delivery Reviews, vol. 44, no. 1, pp. 71-78, 2000.

[41] Food \& Drug Administration, C.B.E.R. (U.S. Department of Health and Human Services, Rockville, Md, USA, 2006).

[42] J. M. Murray, G. C. Fanning, J. L. Macpherson, L. A. Evans, S. M. Pond, and G. P. Symonds, "Mathematical modelling of the impact of haematopoietic stem cell-delivered gene therapy for 
HIV," Journal of Gene Medicine, vol. 11, no. 12, pp. 1077-1086, 2009.

[43] H. L. Malech, P. B. Maples, N. Whiting-Theobald et al., "Prolonged production of NADPH oxidase-corrected granulocytes after gene therapy of chronic granulomatous disease," Proceedings of the National Academy of Sciences of the United States of America, vol. 94, no. 22, pp. 12133-12138, 1997.

[44] A. Aiuti, S. Slavin, M. Aker et al., "Correction of ADA-SCID by stem cell gene therapy combined with nonmyeloablative conditioning," Science, vol. 296, no. 5577, pp. 2410-2413, 2002.

[45] S. Hacein-Bey-Abina, C. Von Kalle, M. Schmidt et al., "LMO2Associated Clonal T Cell Proliferation in Two Patients after Gene Therapy for SCID-X1," Science, vol. 302, no. 5644, pp. 415-419, 2003.

[46] M. G. Ott, M. Schmidt, K. Schwarzwaelder et al., "Correction of X-linked chronic granulomatous disease by gene therapy, augmented by insertional activation of MDS1-EVI1, PRDM16 or SETBP1," Nature Medicine, vol. 12, no. 4, pp. 401-409, 2006.

[47] C. C. Carter, A. Onafuwa-Nuga, L. A. McNamara et al., "HIV1 infects multipotent progenitor cells causing cell death and establishing latent cellular reservoirs," Nature Medicine, vol. 16, no. 4, pp. 446-451, 2010. 

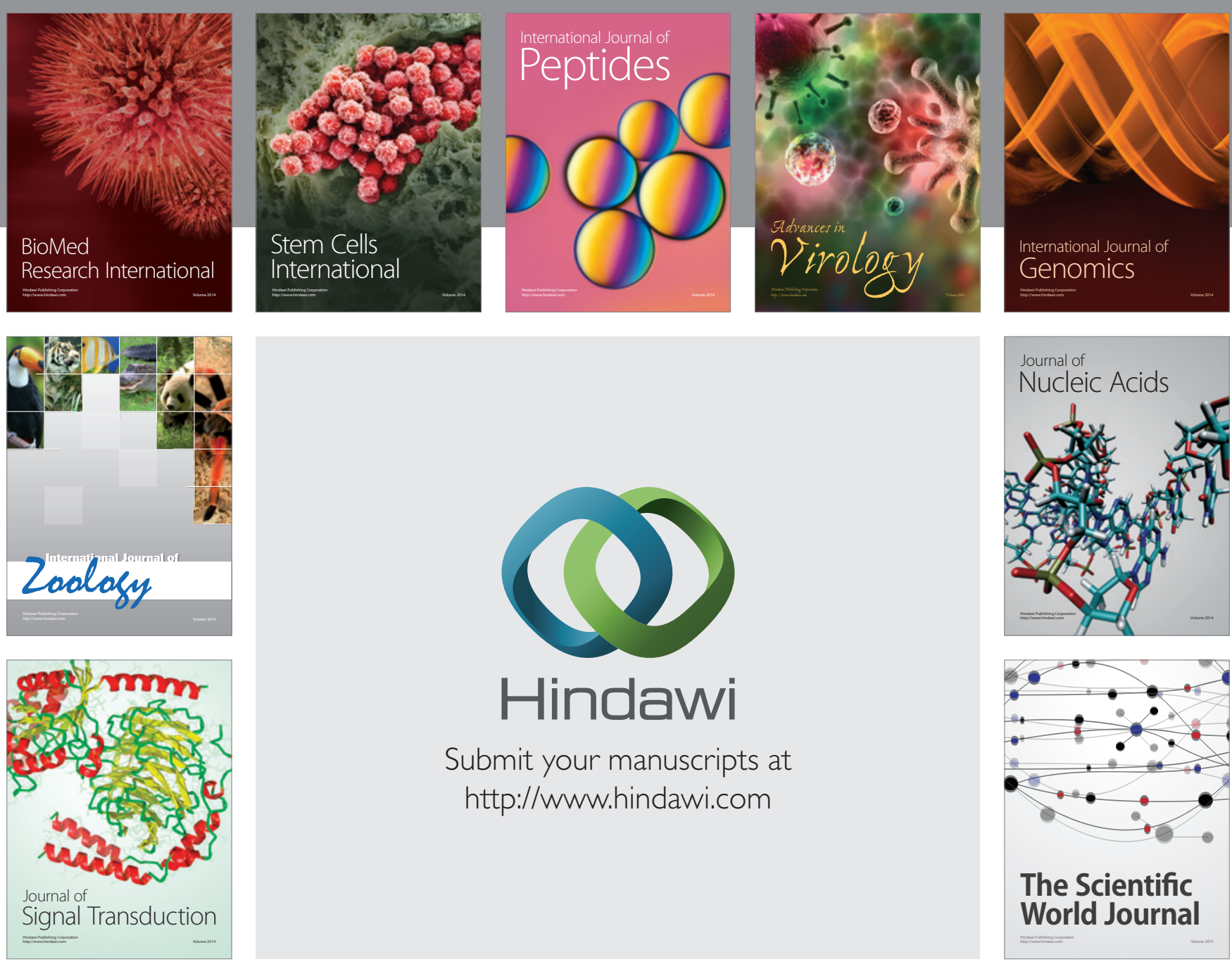

Submit your manuscripts at

http://www.hindawi.com
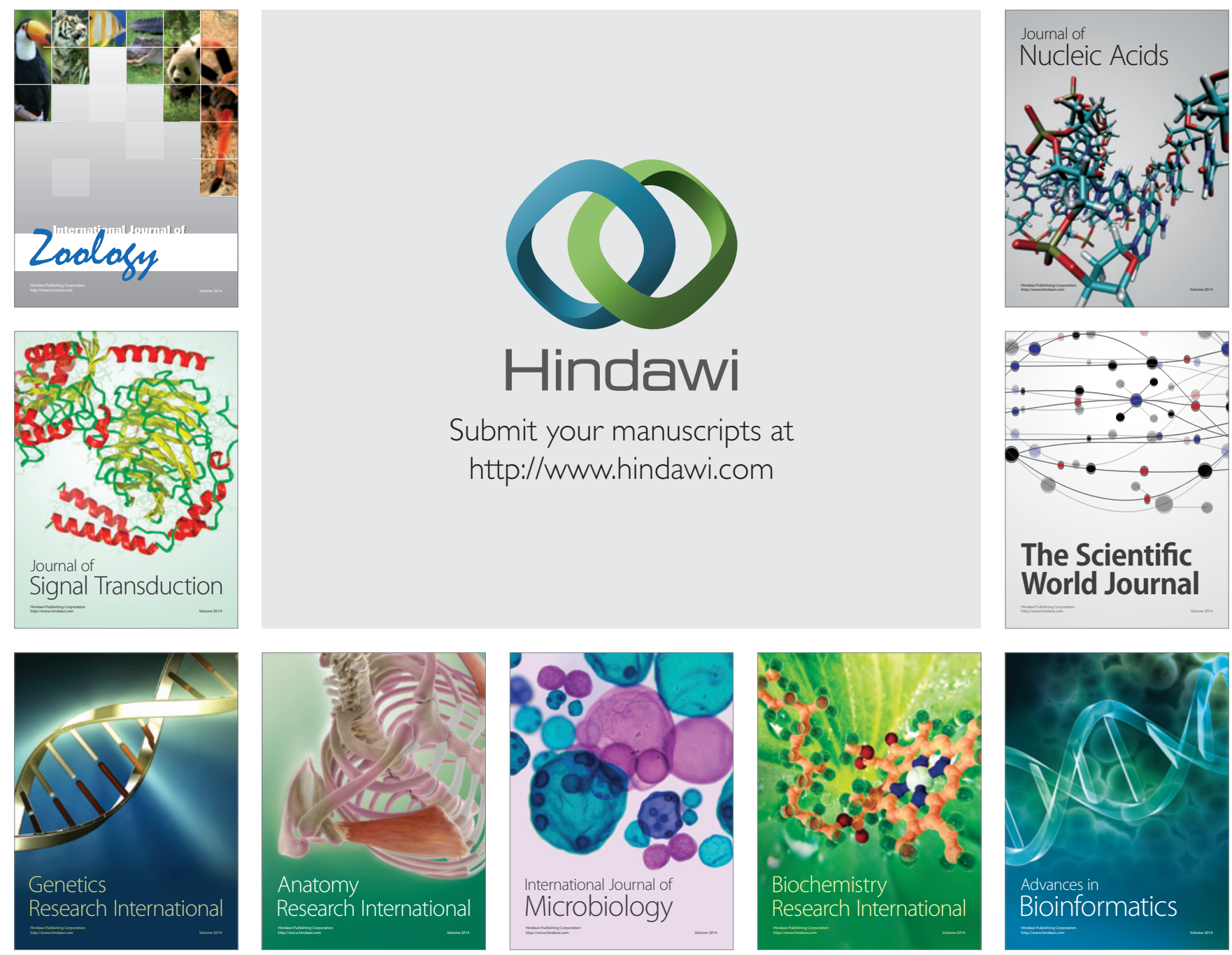

The Scientific World Journal
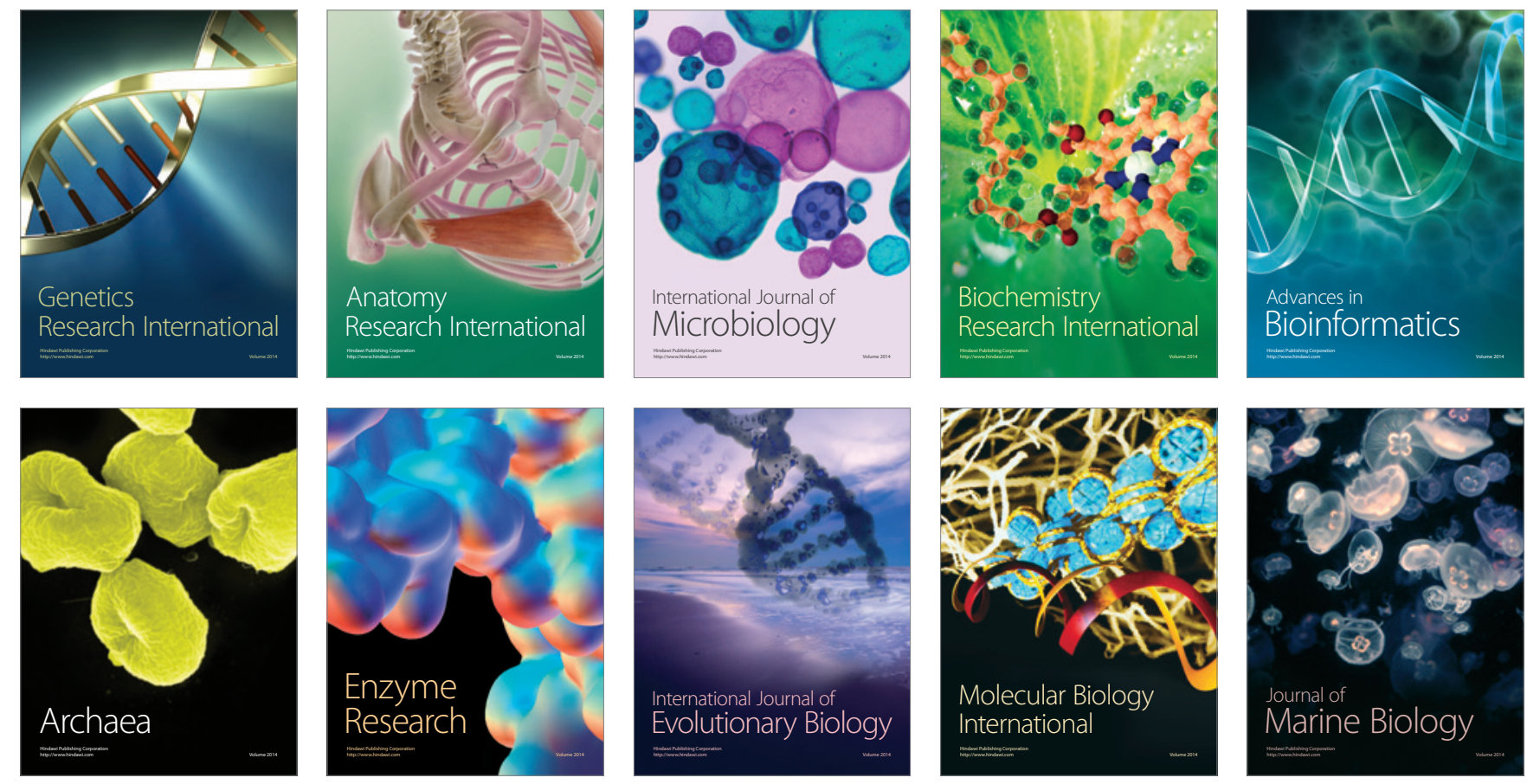